\section{ANNUAL MEETINGS OF THE BRITISH MEDICAL ASSOCIATION.}

\section{To the Editor of THE LANCET.}

SIR,-The discussion attending the late proposed meeting of the above Association at Brighton has brought prominently to my mind a question which for a long time I have been in the habit of pondering over, but could never get a satisfactory answer from any of my personal friends: What is the use, in a scientific point of view, of these annual meetings? And I now take the liberty of asking this question through the medium of your columns, if any member of the Association would kindly give me an answer: What good have such meetings ever done, or what good are they ever likely to do?

The objects of the annual meetings of the British Association, the Social Science, and other kindred societies, are clear and well-defined: to diffuse knowledge and information amongst the public, and to attract other students in the respective fields of inquiry.

The British Medical Association has no such objects. Their meetings are strictly professional, and can never be required for imparting knowledge amongst the laity; though, I suppose, according to the views of the British Medical Journal, at no distant date we may expect to have these meetings enlivened, if not enlightened, by the presence of lady-practitioners.

Now, it would seem to me that for all purposes of receiving and imparting knowledge the medical profession are in a peculiarly favourable position. In fact, such means abound in all parts of the country. We have a large number of well.conducted journals with intelligent editors, willing and anxious at all times to throw open their columns to any one who has any new theory or mode of treatment to propose, or any interesting cases to narrate, which are extensively circulated and read by the profession. There are also in all parts of the kingdom medical schools with their professors and lecturers, who devote their time to the specialties of their respective departments, not to mention the numerous medical societies in London and the provincial towns, many with special objects, where medical subjects are constantly undergoing discussion by the able and intelligent of the profession.

Even supposing that the addresses were invariably delivered by first-class men, it would be difficalt, under the circumstances, to conceive what real good could be derived from such meetings; but as the facts are, as a rule I believe it is pretty generally acknowledged, the reverse, and the addresses are placed in the hands of gentlemen who are only heard of on these occasions-the mere nominees of an overbearing committee;-it would seem to me that the profession at Brighton are quite justified in withholding their cooperation from all such gatherings until it can be shown that some solid advantages to the profession may be reasonably expected to accrue from them.

I am, Sir, your obedient servant,

Brighton, April 22nd, 1876.

WILLIAM KebBeLL, M.D.

\section{DYSIDROSIS : CHEIRO-POMPHOLYX.}

\section{To the Editor of THE LANCET.}

SrR,-I have no desire, even if you would give me space for the purpose, to discuss the matter of cheiro-pompholyx in your columns further than to state:-

1. That whatever Mr. Hutchinson may have said in clinical lectures or the like upon the subject, it is certain that he did not actually publish (i.e., print) anything about it until 1876.

2. That the publication in your columns of any extracts from, or of any lecture delivered by Mr. Hutchinson in 1871 -which I presume will appear in this week's LANCET-will not disprove the fact that I have anticipated him by three years in describing in print, and under the term "dysidrosis," the particular eruption which he has denominated "cheiro-pompholyx." Of course long before 1873, and certainly in 1871, dysidrosis was known and taught as a distinct disease by myself at University College. But our dispute can only be determined by published work.

3. That our concurrence in the employment of similar expressions relative to the character of the disease is not " another of the many instances in which two independent observers, looking at the same facts, come to nearly the same sonclusions, and describe them in nearly the same words," for the sufficient reason that Mr. Hutchinson and I differ entirely as to the pathology of the disease.

4. If the bullæ of the disease be produced by the effusion of serum into the skin, as asserted by Mr. Hutchinson, then (as the disease is not eczema), surely cheiro-pompholyx is a pemphigus, and pemphigus of the hands (and feet) has been acknowledged and described in almost every text-book on skin disease for many a year past, and there is no novelty about Mr. Hutchinson's statements. But,

5. If, as I assert (and I know that this will be confirmed by future observers), the disease begins in the sweat apparatus, and in the early stage of the disease the distension of the sweat-follicles can be plainly traced, then Mr. Hutchinson has held erroneous views of his so-called " cheiro-pompholyx" from the time that his attention was first directed to it.

In conclusion, I desire to say that I did not place Mr. Hutchinson's and my own remarks side by side in parallel columns in order to prove plagiarism on his part, but merely, as I distinctly stated, to demonstrate that we were really dealing in print ' with the same disease-myself in 1873 , and he in 1876.

It may be as well to add that "dysidrosis" is commonly diagnosed as eczema, and especially "gouty" eczema. I am, Sir, your obedient servant, Tilbury Fox.

Harley-street, Carendish-square, W., April 25th, 1876.

\section{To the Editor of THE LANCET.}

SIn, - The eruption for the honour and priority of giving a name to which Mr. Hutchinson and Dr. Tilbury Fox are contending has been familiar to me for the last thirty years, as I should imagine it must have been to very many practitioners.

Of course, when observers so competent connect the eruption with nervous disorder, it must frequently be so; but in all the cases I have seen it has not had this connexion, but has occurred in markedly gouts constitutions, and I looked on it as a local outcome of a gouty seizure as clearly as any of the more ordinary joint affections.

I am at present attending a lady who has since $1813 \mathrm{had}$ repeated attacks both of the sago-grain and bullous forms, the eruption that year having been of the latter. In her case there has been frequent recurrence, but no periodicity and no nervous depression, except such as any irritating external ailment will cause; and she has the credit of having, many years ago, given the name of "pearl sago" to the minor eruption, as, indeed, it would be difficult for any one to avoid doing who wished to describe it either to a friend or doctor.

I confess $I$ cannot at present regard it as a dysidrosis and as it attacks the feet as well as the hands, "cheiro" is not clinically correct.

I am, Sir, your obedient servant,

Ainslie-place, Edinburgh, April 22nd. WM. Comming.

P.S.-I should add, that none of my patients have "perspired too freely," but have rather commented on the dryness of the skin.

\section{DENTAL AN ASTTHETICS AND HEART DISEASE.}

$$
\text { To the Editor of The LaNCET. }
$$

SIR,-A patient who suffers from organic disease of the heart came to me last week and said she was not so well, that she had been a good deal shaken by a prolonged dental operation a few days previously, on which occasion she had eight teeth extracted at one sitting with "the gas," and that there had been some difficulty in bringing her round. I should say that this patient has had rheumatic fever more than once, and that there is a loud, harsh murmur heard all over the precordia ; in brief, she has the physical signs of both aortic and mitral obstruction broadly characterised. Her pulse on Saturday was 144.

I have no intention of assuming that the prolonged administration of the nitrous oxide and the extraction of the 
eight teeth at the one sitting were wrong in this case, because I have no practical knowledge whatever of the use of this gas, and because I believe the operation and the administration of the anæsthetic were undertaken by persons than whom there are none more capable in London. But I am anxious, apropos of this case, to ask a few questions, and it seems to me to be of considerable interest to every member of our profession that these questions should receive clear and definite answers.

1st. Are we or are we not to believe that the existence of great obstruction to the circulation in the form of valvular disease of the heart, such as I have described, counterindicates-wholly or partially-the use of anæsthetics?

2nd. If the preceding question be answered in the affirmative with regard to anæsthetics generally, are we to believe that nitrous oxide is, in these cases, an exception to the general rule?

3rd. If the existence of cardiac disease is a counterindication of the use of anæsthetics, do dentists adopt any means of ascertaining whether patients have or have not heart disease before administering them?

4th. If they do adopt. any such means, what are they? and are they sufficient?

The patient in question assures me that, although three gentlemen were present, feeling the pulse was the only measure adopted to ascertain the condition of the organs of circulation.

5th. If dentists do not adopt any trustwortby measures for ascertaining the existence or non-existence of cardiac disease before administering anæsthetics, ought they not to do so?

I must confess I heard the statement of the patient to whom I have drawn attention with mingled feelings. My first feeling was one of admiration of the nitrous oxide as an anæsthetic. Here was a triumph! A person with a very grave form of heart disease is kept insensible tor a period long enough to extract eight teeth, and is alive to tell the tale! But then I ask myself, Might she not have died? and then what would have been said about the administra. tion of the anæstbettic without first ascertaining whether heart disease did or did not exist?

In connexion with this subject, I observe with satisfaction that a society has been formed which is to consist exclusively of qualified medical men who practise dentistry. As the employment of anæsthetics in dental operations is now so universal, it is of the greatest importance that those who undertake these operations should not only possess a certain amount of mechanical dexterity, but that they should also have undergone such a training in the principles of medicine and in the diagnosis of disease as shall render them competent to detect the existence of disease in which the production of anzsthesia is unsafe or hazardous. No unqualified person should be permitted to make use of anæsthetic agents, although I am assured on good authority that in much of the advertised "painless dentistry" the administration of "the gas" is entrusted sometimes to the dentist's wife! and sometimes to the shop-boy!!

I am, Sir, your obedient servant, I. BURNEY YEO, M.D.

Hertford-street, Mayfair, A pril 12th, 1876.

\section{“THE TREATMENT OF TETANUS BY NERVE- STRETCHING."}

To the Editor of The LANCET.

SIR,-I have read Mr. Callender's remarks as set forth in your journal of the $22 \mathrm{nd}$ inst.; page 576 , with great interest. In turning the subject over in one's mind, the idea has suggested itself that this treatment might be adopted with some prospect of success in those horrid cases of refractory sciatica met with from time to time, cases which successfully resist the influence both of the doctors and physic, however influential the one or potent the other may be. The pain of the operation would be as nothing in comparison with that endured during the paroxysmal attacks so frequent in such cases. I am not sure that this plan of treatment has been before: suggested; if not, I feel sure that the hopeless nature of such eases would fully justify the trial. I am Sir, your obedient servant,

Thomeas Chamemes, F.R.C.P. Edin.

Cheater-square, April 28th, 1876 ,

\section{THE SANITARY CONDITION OF RUGBY SCHOOL.}

To the Editor of The LanceT.

SrR,-I am instructed by the Local Board, with reference to the Report by your Commissioner recently published in your paper and copied into others, that "the sewers are badly laid and ill-ventilated," to give their emohatic denial to such statement, as generally applicable to the sewers of the Local Board, and especially as regards the sewers in the neighbourhood of the school and boarding-houses. I am to add that the Board are extending the ventilation of the sewers, and constructing a flushing-chamber at the terminals of every sewer, and flushing has for a considerable time been systematically carried on; also, that the water supply is from the Board's own works, and not by a com. pany, and the Board are endeavouring to arrange for a constant supply.

I am, Sir, your obedient servant,

Rugby, April 26th, 1876. Theodone M. Wratislaw, Clerk.

** If the drains are not "ill ventilated," why is the Board extending the ventilation of the sewers? The necessity for vigorous flushing is part proof of our statement that the drains are "badly laid." The death-rate of Rugby last year was exceedingly high for a small agricultural town; the cause is to be found in defective drainage and an intermittent water-supply.-ED. L.

\section{Glituatn.}

\section{JOHN HIGGINBOTTOM, F.R.S., F.R.C.S. ENG.}

Mr. Higginbottons died at his residence, Gill-street, Nottingham, on Friday, the 7th of April, at the ripe age of eighty-seven, almost the father of the medical profession. For nearly seventy years he was in professional harness, which he did not throw off until compelled by physical weakness, about three or four years since. From this time there was a gradual but almost imperceptible failure of vital power, unattended by disease, until he quietly passed away, retaining his mental faculties to the last.

Mr. Higginbottom was born at Ashton-under-Lyne, in Lancashire, on the 14th of June, 1788, where his father prac. tised as a solicitor, being much respected, and acquiring the appellation, "the honest lawyer." When about seven years of age he was sent to a school kept by an unbeneficed clergyman at Ollerton, in Cheshire, whence he was removed to a school in his native town, the master of which believed too much in the efficacy of the ferule as a means of im. parting knowledge. This severity had a bad effect upon a young, delicate, and nervous boy, and prevented him making progress, so he was eventually placed at a school in Chester kept by Mr. Segismund Stolterforth, whom he always re garded and esteemed. Upon leaving this school he was placed in his father's office, his parents having determined that he and his two brothers should follow a profession. Mr. Higginbottom much disliked the confinement at the desk, and as often as he could he stole away to enjoy his favourite amusement-angling; a love for the sport continuing through life. He enjoyed all its literature, especially that of the "gentle Isaac." Mr. Higginbottom was of opinion that a real angler was born such: " piscator nascitur, non fit." He had, too, a taste for drawing, which he assiduously cultivated when young and practised through life. This acquirement was of great service to him in the profession he ultimately adopted, and also in his scientific investigations, as well as a souree of delight and solace.

Finding he had no taste for law, his parents suggested medicine and surgery for his future study. He consented to be apprenticed to an uncle who was a surgeon at Stockport, an eccentric, whimsical, and tyrannical bachelor. The medical student of to-day who passes from school to college, and learns his pharmacy in a comfortable class. room, has no conception of the hardships of an apprentice airty years ago. Alluding to this, Mr. Higginbottom in 